\title{
Outcomes of radical surgical management in liver hydatid cysts: 7 years center experience
}

\author{
Wael Mansy', Morsi Mohamed ${ }^{1}$, Sameh Saber ${ }^{2}$ \\ ${ }^{1}$ Hepatobiliary Surgery, General Surgery Department, Zagazig University, Zagazig 44511, Egypt. \\ ${ }^{2}$ Intervention Radiology, Zagazig University, Zagazig 44511, Egypt.
}

Correspondence to: Dr. Wael Mansy and Morsi Mohamed, Hepatobiliary Surgery, General Surgery Department, Zagazig University, Advanced Hepato-Pancreateco-Biliary Center, Koliat Al Tob Street, Zagazig 44511, Egypt.

E-mail:drwaelmansy@hotmail.com; drmorsi@yahoo.com

How to cite this article: Mansy W, Mohamed M, Saber S. Outcomes of radical surgical management in liver hydatid cysts: 7 years center experience. Mini-invasive Surg 2018;2:36. http://dx.doi.org/10.20517/2574-1225.2018.48

Received: 7 Jul 2018 First Decision: 12 Jul 2018 Revised: 27 Aug 2018 Accepted: 30 Sep 2018 Published: 23 Oct 2018

Science Editor: Charles F. Bellows Copy Editor: Cai-Hong Wang Production Editor: Zhong-Yu Guo

\begin{abstract}
Aim: To evaluate our experience of radical treatment in management of liver hydatid cyst. As liver is considered the organ most frequently infected with hydatid disease.

Methods: We performed a retrospective study concerning surgical management of liver hydatid cyst at Advanced Hepato-Pancreateco-Biliary Center. Our study done from June 2011 to May 2018 on 103 patients presented with hepatic hydatid cyst.

Results: Total pericystectomy was carried out in 80 (77.67\%) patients; while hepatic resection was carried out in 14 (13.59\%) patients. Laparoscopic management was done in $6(5.82 \%)$ patients ( 5 cases with total pericystectomy and 1 case with sub-total pericystectomy and omentoplasty). Twenty-one patients developed post-operative complications, four patients suffered from biliary leak. There was no mortality. Follow-up period ranged from 6 to 60 months with no recurrence.
\end{abstract}

Conclusion: Radical surgical procedures were safe and effective in management of hepatic hydatid cyst when it was done by experienced surgeons, with lower morbidity rates and no recurrence.

Keywords: Liver hydatid cysts, pericystectomy, hepatic resection, cystobiliary communications, recurrent hydatid

\section{INTRODUCTION}

Echinococcus spp. is responsible for Hydatidosis. Accidental hosts are infected with one or more cysts in different body sites, mainly in the liver ${ }^{[1]}$. The disease is endemic in sheep rearing countries as in the

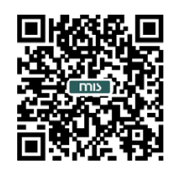


Mediterranean Sea and Middle East where there is contact with infected animals ${ }^{[2]}$. During our study, we discovered increasing incidence of liver hydatid disease. And surprisingly, we get no feedback regarding animal contact in some patients. Camels were the only contact animal in other patients.

Different management modalities were discussed before in literature, but surgery remains the standard treatment. Operative modalities range from complete resection (e.g., total pericystectomy or hepatectomy) to minimal invasive procedures (e.g., percutaneous aspiration of cysts) ${ }^{[3]}$. More recently, laparoscopic approaches take a hand in the treatment of hepatic hydatid cysts ${ }^{[4]}$.

Choosing the appropriate modality for management depends on several factors: number \& site of the cysts, patient general condition, type of hospital in which the surgery is performed, including the possibility of intensive postoperative care and the surgeon's expertise ${ }^{[5]}$.

Radical treatment modality focuses on near total or total hepatic adventitia resection with or without hepatic parenchyma resection associated, which avoids residual cavity ${ }^{[6]}$.

Here in our study, we assess our experience in radical treatment especially total pericystectomy in management of hepatic hyatid cyst.

\section{METHODS}

\section{Patients and methods}

In this retrospective study, we analyzed 103 patients with hydatid cyst managed at the Advanced HepatoPancreatico Biliary Center, Zagazig University Hospitals, from June 2011 till May 2018. All data as clinical, radiological, laboratory, operative, and post-operative were recorded. Comorbidity, operative morbidity and mortality, surgical procedure, length of postoperative hospital stay were also recorded.

The diagnosis was made mainly on radiological appearance (ultrasonography was the imaging of choice). In doubtful cases we also combined radiology with serology (enzyme-linked immunosorbent assay) and Triphasic CT which was used to assess location, diameter and number of cysts. We used plain $\mathrm{x}$-ray chest to identify lung hyatid cyst. Magnetic resonance cholangiopancreatography (MRCP) was performed for patients with hydatid cyst more than $5 \mathrm{~cm}$ in diameter, recurrent and multiple cysts to assess cysto-bilary communications. Endoscopic retrograde cholangiopancreatography (ERCP) restricted to patients presented with preoperative obstructive jaundice.

Albendazole $400 \mathrm{mg}$ twice daily was prescribed for two weeks prior to surgery to inactivate the organism. During the follow up period Albendazole was given with the same doses for 3 and 6 months in complicated and recurrent cases. In cirrhotic patients we reduced the dose to $200 \mathrm{mg}$ twice daily for 1 week preoperative and for 3 months postoperative.

\section{Surgical technique}

Surgeries were done by trained surgeons. Epidural catheter was used for postoperative pain management. J shaped incision "Makuuchi" was the chosen approach for good exposure. But, bilateral subcostal incision used in cases needed splenectomy. Complete liver mobilization, identification of the cyst (site and number), search for other associated cysts (intestine or kidney) followed by gauze towels soaked in hypertonic saline used to isolate the lesion and safeguard against the risk of spillage of cyst contents into the peritoneal cavity, were the routine steps.

In cases where the cyst was deep intra-parenchymal, we used intra-operative U/S to identify the proper site. Harmonic shears were used to achieve good haemostasis during liver parenchyma dissection. Also, in 

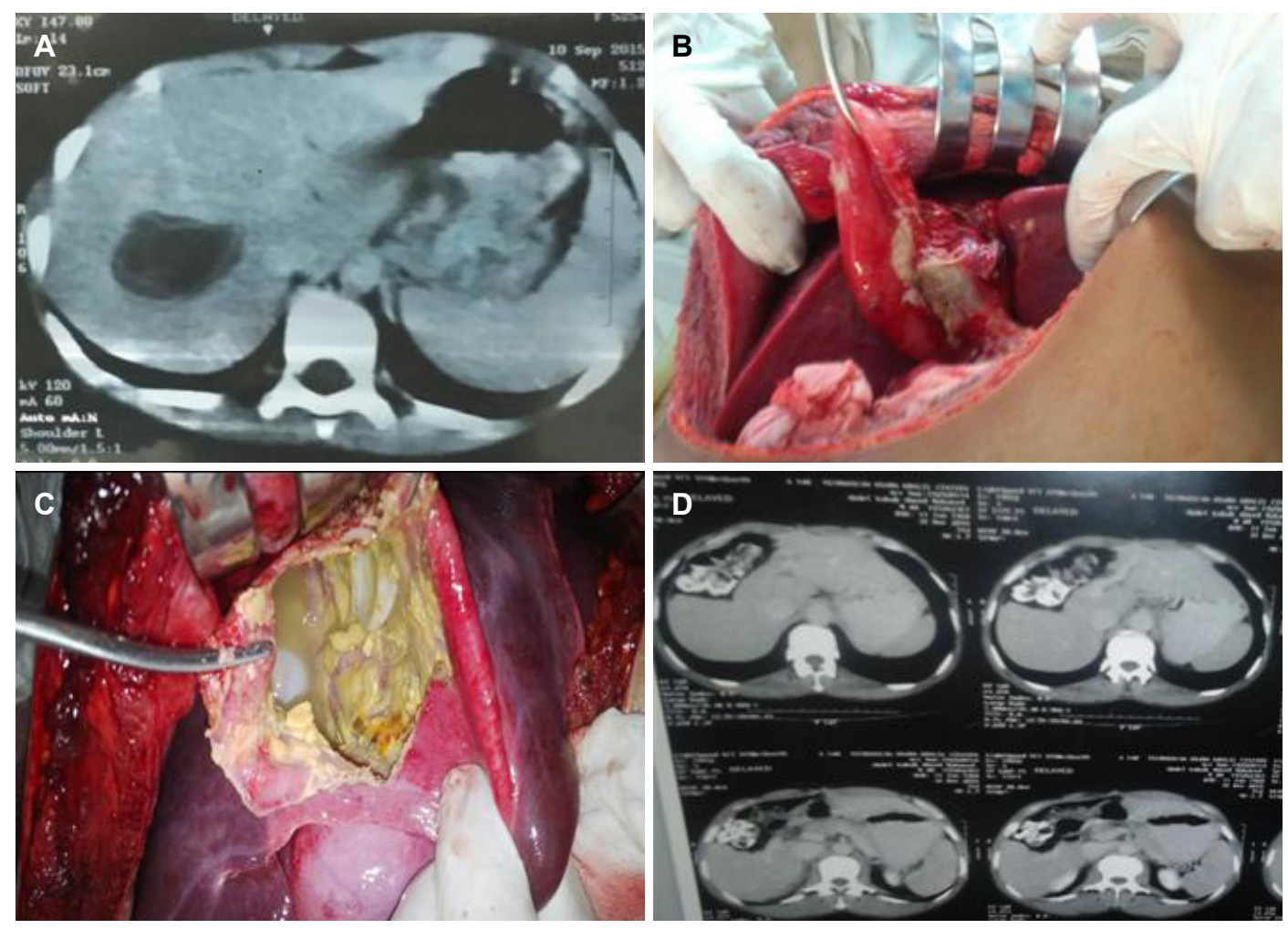

Figure 1. A: Intra-parenchymal hydatid cyst in female 9 years old; B: ruptured hydatid cyst in 17 years male; C: huge central hydatid cyst in 45 years male; D: CT 2 years after huge centeral hydatid removal

order to reduce bleeding, inflow control was done (Pringle maneuver) in some cases.

Surgical procedures were radical surgery in the form of total pericystectomy, sub-total pericystectomy and liver resection. Pericystectomy is performed with closed or open, total or sub-total method. The closed procedure was used in superficial cysts or exophytic cysts without opening the cyst. Open method was performed in deep cysts or cysts closely related to the hepatic veins or inferior vena cava (IVC). It was done by puncture of the cyst, suction of the fluid, removal of endocyst and cavity irrigation with hypertonic saline [Figure 1].

In cases of hard pericysts adherent to main vessels, especially to the IVC, we stopped dissection just before the vascular plane leaving a small part of the cyst wall (sub-total). Omentoplasty was done to prevent fluid re-accumulation and avoid recurrence.

In laparoscopic procedure, all patients were positioned in the French position and semi-left lateral position. In right side lesions, four to five ports were placed under direct visualization. A $10-\mathrm{mm}$ port is placed $2-3 \mathrm{~cm}$ above and to the right of umbilicus for camera. Two $12-\mathrm{mm}$ ports were placed about $5 \mathrm{~cm}$ to the left and right side of camera port and one or two 5-mm ports were placed below right and/or left costal margin for liver retraction by the assistant. In left sided lesions, the same trocars were placed in the same positions but shifted $1-2 \mathrm{~cm}$ to the left. Irrigation of the abdominal cavity was performed with hypertonic saline to safeguard against spillage in central cases that would underwent sub-total excision.

We sent the specimen to histopathology to confirm the diagnosis. Follow up was done at 6-60 months postoperative including physical examination, laboratory testing, ultrasonography and triphasic CT to assess the success of surgery, liver regeneration in major cases and to detect recurrence. 


\section{RESULTS}

Our study included 103 patients with hydatid disease. 32 (31.068\%) were males and 71 were (68.932\%) females. The median age at presentation was 35 (range 10-65) years. 65 (63.11\%) patients presented with symptoms. The most common symptom was abdominal pain presented in all symptomatic patients. Serology test was positive in $76(73.79 \%)$ patients. Ultrasound was positive in all patients.

Cyst was solitary in $74(71.84 \%)$ cases. The most common size of the cyst was 7-10 $\mathrm{cm}$ presented in $62(60.19 \%)$ patients. Huge cyst more than $20 \mathrm{~cm}$ was found in 4 patients. Most of the cysts were in the right lobe 69 (66.99\%) cases. A total of $76(73.79 \%)$ patients had deep cysts [Table 1].

We faced complicated cysts in 30 patients, as well as ruptured cysts in 3 patients (25 years male patient with ruptured cyst inside the $\mathrm{CBD}, 17$ years male patient with ruptured central hydatid cyst discovered incidentally during operation, which was at the area of the porta-hepatis and 35 years female patient with ruptured cyst at segment IV discovered incidentally during operation). Infected cysts were found in 12 patients (7 of them were due to percutaneous ultrasound (US) guided diagnostic aspiration fine needle aspiration cytopathology).

We also managed recurrent cysts in 15 cases (4 M \& $11 \mathrm{~F}$ ); 7 cases with past history of US guided drainage and 8 cases with past history of conservative surgery (endocystectomy). Two patients after US guided aspiration had more than 1 cyst; 1 male patient had 3 cysts ( 1 huge in the peritoneum, 1 in the liver and 1 in the spleen) and 1 female with 2 cysts in the left lobe. Two females also after endocystectomy had more than 1 cyst; 1 with 3 cysts ( 2 of them were biliary cyst) and the other one had 2 cysts 1 in the left lobe and 1 in the right lobe [Table 2].

Total pericystectomy was carried out on $80(77.67 \%)$ patients [open method in 49 (47.57\%) patients and closed method in 31 (30.1\%) patients]. Hepatic resection was carried out on 14 (13.59\%) patients and 3 (4.3\%) patients required a subtotal pericystectomy with omentoplasty (where the IVC and hepatic veins forming the posterior wall of the cyst).

Laparoscopic management used in $6(5.82 \%)$ patients (laparoscopic total pericystectomy in 5 cases and laparoscopic subtotal pericystectomy and omentoplasty in one patient).

Intra-operative US was done in 4 patients in whom the cyst was totally intra-parenchymal and not palpable. Intra-operative cholangiography done in 9 patients. While intra-operative ERCP and stenting was done in one female patient, that had huge cyst including CBD. Cysto-biliary communications were found in $78(82.6 \%)$ patients. Major communications were found in $42(40.78 \%)$ patients. However minor cystobiliary communications were presented in $36(34.95 \%)$ patients.

The mean operative time was $170 \mathrm{~min}$. The average intra-operative blood loss was less than $600 \mathrm{~mL}$. Thirty-two patients needed packed RBCs transfusion while 39 patients needed FFP transfusion. The mean hospital stay was 7 days in all patients. The mean ICU stay was 2 days in $18(17.48 \%)$ patients.

Twenty-one (20.39\%) patients developed post-operative complications with no mortality or recurrence. Postoperative bleeding occurred in female patient after $10 \mathrm{~h}$ post operatively which re-explored (bleeding was from liver bed and slipped ligature from one of the varices at the splenic bed).

Four patients developed post-operative bile leaks (one of them with right hepatectomy, biloma was at the cut-surface that needed percutaneous US guided pigtail catheter drainage, removed after 2 weeks. The other 3 were managed conservatively). 
Table 1. Characters of the hepatic hydatid cyst

\begin{tabular}{ll}
\hline Characters & Number \\
\hline Type & \\
Clear & $29(38.16 \%)$ \\
Multivesicular & $74(71.84 \%)$ \\
Size & \\
S6 cm & $22(21.36 \%)$ \\
$7-10 \mathrm{~cm}$ & $62(60.19 \%)$ \\
$11-20 \mathrm{~cm}$ & $15(14.56 \%)$ \\
$>$ 20 cm & $4(3.89 \%)$ \\
& \\
Cyst number & \\
One cyst & $74(71.84 \%)$ \\
Two cysts & $19(18.44 \%)$ \\
More than 2 cysts & $10(9.72 \%)$ \\
Associations & $14(13.59 \%)$ \\
CBD & $2(1.94 \%)$ \\
Spleen & $10(9.71 \%)$ \\
Peritoneum & $2(1.94 \%)$ \\
Location & \\
RT lobe & $69(66.99 \%)$ \\
Whole & $4(3.88 \%)$ \\
RT. Post Seg. VI, VII & $17(16.5 \%)$ \\
RT. Ant Seg. V, VIII & $6(5.82 \%)$ \\
Segment V & $8(7.77 \%)$ \\
Segment VI & $18(17.48 \%)$ \\
Segment VII & $9(8.74 \%)$ \\
Segment VIII & $7(7.8 \%)$ \\
LT lobe & $21(20.39 \%)$ \\
LT Lat. Seg. II, III & $16(15.53 \%)$ \\
Segment IV & $5(4.86 \%)$ \\
Central liver & \\
Segment IV, V, VIII & $4(3.88 \%)$ \\
Bilobar & $9(8.74 \%)$ \\
Site & \\
Superficial & $27(26.21 \%)$ \\
Vasculo-biliary cyst & $76(73.79 \%)$ \\
Non-complicated & $73(70.87 \%)$ \\
Complicated cysts before surgery & $30(29.13 \%)$ \\
Rupture & $3(2.91 \%)$ \\
Infection & $12(11.65 \%)$ \\
Recurrence & $15(14.56 \%)$ \\
Complicated cysts After US guided drainage & $7(6.8 \%)$ \\
Complicated cysts After endo-cystectomy & $8(7.76 \%)$ \\
\hline &
\end{tabular}

Eight patients developed right sided pleural effusion, managed by albumin and diuretics. Four patients developed ascites due to liver cirrhosis and portal hypertension were also managed by albumin and diuretics. We faced wound infection in 5 patients. While incisional hernia in 3 patients developed 1 year after surgery [Table 3].

\section{DISCUSSION}

Hydatid disease increased in sheep raising areas ${ }^{[7]}$. The increased number of people immigrated from contaminated areas as Iraq and Syria because of war as well as dogs in the street and contamination of vegetables with dogs' excreta, enhance the incidence of hydatid disease in our country lately.

The hydatid cyst presentation is always asymptomatic for many years, as it enlarges slowly ${ }^{[8]}$. In our series, 38 (36.89\%) patients were asymptomatic at the time of diagnosis. Symptoms arise either from pressure effects on adjacent organs or when a complication occurs ${ }^{[9]}$. The sensitivity of US in liver hydatid disease diagnosis was $100 \%$. Affection of liver lobes by Hydatid disease was more in the right lobe ${ }^{[10]}$, which was matching with our patients $69(66.99 \%)$. The cysts are more commonly solitary as was the case in $74(71.84 \%)$ of our patients. 
Table 2. Characters of recurrent cases managed by total pericystectomy

\begin{tabular}{|c|c|c|c|c|c|c|c|c|}
\hline \multirow{2}{*}{$\mathbf{N}$} & \multicolumn{4}{|c|}{ Demographic data } & \multicolumn{4}{|c|}{ Cyst characters } \\
\hline & Age & Sex & Symptoms & Co-morbidity & No. & Size & Location & Associations \\
\hline \multicolumn{9}{|c|}{ Seven cases with past history of US guided drainage } \\
\hline 1 & 55 & M & $\begin{array}{l}\text { Abdominal pain } \\
\text { Mass }\end{array}$ & HPN & 3 & $\begin{array}{l}\text { Peritoneum > } 20 \mathrm{~cm} \\
\text { Spleen } 8 \mathrm{~cm} \times 7 \mathrm{~cm} \\
\text { Liver } 6 \mathrm{~cm} \times 6 \mathrm{~cm}\end{array}$ & Seg. II, III & $\begin{array}{l}\text { Peritoneum } \\
\text { Spleen }\end{array}$ \\
\hline 2 & 22 & $\mathrm{~F}$ & Abdominal pain & Non & 1 & $7 \mathrm{~cm} \times 7 \mathrm{~cm}$ & Seg. VIII & Non \\
\hline 3 & 35 & $\mathrm{~F}$ & $\begin{array}{l}\text { Abdominal pain } \\
\text { Nausea \& Vomiting }\end{array}$ & Non & 1 & $8 \mathrm{~cm} \times 8 \mathrm{~cm}$ & Seg. V & GB stones \\
\hline 4 & 28 & M & Abdominal pain & $\begin{array}{l}\text { Liver cirrhosis } \\
\mathrm{HCV}+\mathrm{ve}\end{array}$ & 1 & $6 \mathrm{~cm} \times 7 \mathrm{~cm}$ & Seg. VI & Non \\
\hline 5 & 30 & $\mathrm{~F}$ & Abdominal pain & Non & 1 & $8 \mathrm{~cm} \times 8 \mathrm{~cm}$ & Seg. II, III & Non \\
\hline 6 & 35 & $\mathrm{~F}$ & Abdominal pain & Non & 1 & $7 \mathrm{~cm} \times 7 \mathrm{~cm}$ & Seg. VII & Non \\
\hline 7 & 48 & $\mathrm{~F}$ & $\begin{array}{l}\text { Abdominal pain } \\
\text { Fever }\end{array}$ & Cardiac & 2 & $\begin{array}{l}6 \mathrm{~cm} \times 7 \mathrm{~cm} \\
3 \mathrm{~cm} \times 3 \mathrm{~cm}\end{array}$ & Seg. III, III & Non \\
\hline \multicolumn{9}{|c|}{ Eight cases with past history of endocystectomy } \\
\hline 1 & 23 & $\mathrm{~F}$ & Abdominal pain & Non & 1 & $7 \mathrm{~cm} \times 8 \mathrm{~cm}$ & Seg. VII & Biliary Fistula \\
\hline 2 & 32 & $\mathrm{~F}$ & Abdominal pain & Non & 1 & $7 \mathrm{~cm} \times 6 \mathrm{~cm}$ & Seg. VI & Non \\
\hline 3 & 25 & $\mathrm{~F}$ & $\begin{array}{l}\text { Abdominal pain } \\
\text { Nausea \& Vomiting }\end{array}$ & Non & 1 & $8 \mathrm{~cm} \times 8 \mathrm{~cm}$ & Seg. VIII & Non \\
\hline 4 & 50 & $\mathrm{~F}$ & $\begin{array}{l}\text { Incisional hernia } \\
\text { Abdominal pain }\end{array}$ & Non & 3 & $\begin{array}{l}\text { RT } 9 \mathrm{~cm} \times 8 \mathrm{~cm} \\
7 \mathrm{~cm} \times 7 \mathrm{~cm} \\
\text { LT } 6 \mathrm{~cm} \times 5 \mathrm{~cm}\end{array}$ & $\begin{array}{l}2 \text { RT Seg. VIII } \\
\text { Seg. VI } \\
1 \text { LT Seg.IV }\end{array}$ & $\begin{array}{l}\text { Past history of splenectomy } \\
\text { Right biliary cyst after } \\
\text { endocystectomy }\end{array}$ \\
\hline 5 & 45 & M & Abdominal pain & DM & 1 & $7 \mathrm{~cm} \times 8 \mathrm{~cm}$ & Seg. IV & Non \\
\hline 6 & 28 & $\mathrm{~F}$ & $\begin{array}{l}\text { Abdominal pain } \\
\text { Nausea \& Vomiting }\end{array}$ & Non & 1 & $6 \mathrm{~cm} \times 8 \mathrm{~cm}$ & Seg. II, III & GB stones \\
\hline 7 & 27 & $\mathrm{~F}$ & Abdominal pain & Non & 2 & $\begin{array}{l}\text { LT } 6 \mathrm{~cm} \times 6 \mathrm{~cm} \\
\text { RT } 7 \mathrm{~cm} \times 8 \mathrm{~cm}\end{array}$ & $\begin{array}{l}\text { LT Seg. IV } \\
\text { RT Seg. VII }\end{array}$ & Non \\
\hline 8 & 55 & M & Abdominal pain & $\mathrm{HCV}+\mathrm{ve}$ & 1 & $8 \mathrm{~cm} \times 9 \mathrm{~cm}$ & Seg II, III & Biliary Fistula \\
\hline
\end{tabular}

Table 3. Postoperative outcomes

\begin{tabular}{lll}
\hline Outcome & & Number \\
\hline Hospital stay & 7 days $(5-10$ days $)$ & $18(17.48 \%)$ \\
ICU stay & 2 days $(1-3$ days $)$ & \\
Operative time & $170 \mathrm{~min}(120-250 \mathrm{~min})$ & \\
Blood loss & $600 \mathrm{~mL}(300-2000 \mathrm{~mL})$ & $32(31.07 \%)$ \\
Blood transfusion & $2-4$ units & $39(37.86 \%)$ \\
Fresh frozen plasma & $2-4$ units & $21(20.39 \%)$ \\
Complications & & $1(0.97 \%)$ \\
Bleeding & & $4(3.88 \%)$ \\
Biliary leak & & $4(3.88 \%)$ \\
Chest infection & & $8(7.76 \%)$ \\
Pleural effusion & & $4(3.88 \%)$ \\
Ascites & & $5(4.85 \%)$ \\
Wound infection & & $1(0.97 \%)$ \\
Burst abdomen & & $3(2.91 \%)$ \\
Incisional hernia & & \\
\hline
\end{tabular}

${ }^{1}$ Patient had more than one complication

Assessment of cysto-biliary communication presence via preoperative detection was essential. Recurrent episodes of cholangitis and Large cysts occupying several liver segments are highly suggestive of cystobiliary communications, and a search for the fistula should be meticulous ${ }^{[11]}$. In our series MRCP was mandatory for all patients for detection of cysto-biliary communications.

Since effective anti-parasitic medical treatment has not yet proved to treat and to effectively cure the disease, the optimal treatment for hepatic hydatid cyst is surgery ${ }^{[12]}$. Treatment of hepatic hydatid cyst 
should be focused on parasite elimination, and treatment of both the adventitia as well as the cavity.

Total or near total pericystectomy is the chosen treatment for hepatic hydatid cyst, because it is the only management modality that treats the disease integrally with low morbidity and mortality ${ }^{[13]}$. If we don't resect the infected adventitia well, which is known to contain exogenous vesicles, that may lead to relapse of the disease. Due to this reason radical treatment prevents residual cavity disease and thus prevents relapse ${ }^{[9,13]}$. In our study, radical procedure was done in $96.12 \%$ of the patients (liver resection in $14.59 \%$, total pericystectomy in $77.67 \%$ and laparoscopic total pericystectomy in $4.85 \%$ ). In a study of Marco et al.$^{[6]}$, a radical treatment was performed for $93 \%$, and for $81 \%$ of these patients, total or near total cystectomy was done.

In addition to ordinary open surgical techniques, the laparoscopic approach has been used as a new modality for hydatid cyst treatment.

The laparoscopic approach on open approach affords a short hospital stay, less invasiveness, lower incidence of wound infection and less postoperative pain ${ }^{[14]}$. Disadvantages of laparoscopic technique are limited manipulation, difficult thick viscous content aspirating, increased risk of cyst content spillage and the difficult approach deeply-seated lesions ${ }^{[15]}$. Note that centrally located cysts carry a high risk of bleeding, so we should think in conventional open method, for its management ${ }^{[16]}$.

Radical hydatid cyst treatment showed better results and low risk for complications ${ }^{[17]}$. In our study, the average intra-operative bleeding was less than $600 \mathrm{~mL}$, ranging from $300 \mathrm{~mL}$ to $2000 \mathrm{~mL}$. About $31.07 \%$ of the patients required an intraoperative blood transfusion. Less than $20 \%$ of the patients required hospitalization in ICU during the first $24 \mathrm{~h}$ postoperatively.

Complicated hydatid liver cysts was found in $15 \%$ to $60 \%$ of patients at the time of diagnosis ${ }^{[18]}$. We managed 30 (29.13\%) patients with complicated hydatid cyst. The most important cases were the 8 cases that recurrent after incomplete resection (endocystectomy and drainage). Three of the cases were presented with biliary complications ( 1 with biliary cyst and 2 with biliary fistula).

The type of surgery: either conservative method (deroofing, drainage) or radical surgery (pericystectomy and hepatectomy) is the major factor for hydatid cyst recurrence ${ }^{[18]}$. Aydin et al. ${ }^{[19]}$ comparative retrospective study on 242 patients described significantly higher morbidity and recurrence rates in patients managed by conservative surgery (11\% vs. 3\%; $24 \%$ vs. 3\%). In another study by Tagliacozzo et al. ${ }^{[20]}$, from 454 patients, 214 were managed with conservative surgery (external drainage, marsupialization or omentoplasty), while the remaining 240 managed with radical surgery. Morbidity and recurrence rates were significantly higher in the group that was managed conservatively. In our study no recurrence was detected during the follow up period.

Biliary leakage and fistulas are the main immediate post-operative complications after conservative procedures, beside septic complications of the residual cavity. A pericyst left in situ (especially if thick and calcified) represents two major obstacles. First, delay liver regeneration filling the residual cavity, leading to serum and blood accumulation or liver abscess formation. Second, pericyst persistence may hide possible biliary communication in the residual cavity leading to biliary fistula, which occurs in up to $50 \%$ of patients after conservative managemenet ${ }^{[3]}$.

However radical procedure advantages in this particular issue allow exact detection and safe suture of biliary and vascular branches in the healthy parenchyma which definitely reduce the risk of biliary leak and blood collection. Spontaneous reduction of the residual cavity by liver regeneration would happen ${ }^{[21]}$.

Albendazole may play a role to prevent recurrences after surgery using $400 \mathrm{mg}$ twice daily for 3-6 months. 
According to the WHO, antiparasitic chemotherapy treatment is considered an important indication to prevent secondary echinococcosis and reduce the risk of recurrence. In patients who didn't take albendazole, recurrence rate was $18.75 \%$, compared to $4.16 \%$ recurrence rate in patients who received albendazole therapy ${ }^{[22]}$. In our study, we give the patients albendazole $400 \mathrm{mg}$ twice daily for $1-2$ weeks before surgery, and postoperative for 3 months in uncomplicated cases and 6 months for complicated cases.

In conclusion, pericystectomy is a safe and effective management modality for liver hydatid cyst either complicated or uncomplicated. This attributed to no mortality, less morbidity and no recurrence especially when done by experienced surgeons and specialized centers with appropriate equipment.

\section{DECLARATIONS}

\section{Acknowledgments}

The authors would like to thank the Advanced Hepato-Pancreateco-Biliary Center team for their continuous support to achieve patients data.

\section{Authors' contributions}

Design, literature research, data acquisition, drafted manuscript: Mansy W, Mohamed M, Saber S

Data analysis: Mohamed M

Revised manuscript: Mansy W

\section{Availability of data and materials}

Patients were identified using Advanced Hepato-Pancreateco-Biliary Center database. Data were collected retrospectively through systematic review of patient charts and imaging. The de-identified data is available by contacting the corresponding author Associate Professor wael mansy.

\section{Financial support and sponsorship}

None.

\section{Conflicts of interest}

All authors declared that there are no conflicts of interest.

\section{Ethical approval and consent to participate}

Not applicable.

\section{Consent for publication}

Not applicable.

\section{Copyright}

(c) The Author(s) 2018.

\section{REFERENCES}

1. Larrieu E. Risks factors for hidatidosis in children of Rio Negro Province. A study of cases and control. Ann Trop Med Parasitol 2002;96:43-52.

2. Ayles HM, Corbett EL, Taylor I, Cowie AGA, Bligh J, et al. A combined medical and surgical approach to hydatid disease: 12 years' experience at the hospital for tropical diseases, London. Ann R Coll Surg Engl 2002;84:100-5.

3. Tagliacozzo S, Miccini M, Gregori M, Bonapasta SA, Tocchi A. Surgical management of hyatid disease of the liver: 25 years of experience. Am J Surg 2011;201:797-804.

4. Verma GR, Bose SM. Laparoscopic treatment of hepatic hydatid cyst. Surg Laparosc Endosc 1998;8:280-2.

5. Chautems R, Leo H, Gold B, Giostra E, Poletti P, et al. Surgical management and long-term outcome of complicated liver hydatid cysts caused by Echinococcus granulosus. Surgery 2005;137:312-6.

6. Marco H, Abelleira M, Vanerio P, Ettlin A, San Martin G, et al. Radical treatment of hepatic hydatid cyst: results of total and near-total 
pericystectomy. J Liver Clin Res 2017;4:1039.

7. Balik AA, Basoglu M, Celebi F, Oren D, Polat KY, et al. Surgical treatment of hydatid disease of the liver: review of 304 cases. Arch Surg 1999;134:166-9.

8. Magistrelli P, Masetti R, Coppola R, Messia A, Nuzzo G, et al. Surgical treatment of hydatid disease of the liver: a 20-year experience. Arch Surg 1991;126:518-23.

9. Silva MA, Mirza DF, Mayer AD, Bramhall SR, McMaster P, et al. Treatment of hydatid disease of the liver, evaluation of a UK experience. Dig Surg 2004;21:227-34.

10. Dervenis C, Delis S, Avgerinos C, Madariaga J, Milicevic M. Changing concepts in the management of liver hydatid disease. J Gasterointest Surg 2005;9:869-77.

11. Erguney S, Tortum O, Taspinar AH, Ertem M, Gazioğlu E. Complicated hydatid cysts of the liver [extra data]. Ann Chir 1991;45:584-9.

12. Brough W, Hennessy O, Rickard MD, Lightowlers MW, Kune GA. Preoperative albendazole therapy for recurrent hydatid disease. Aust NZ J Surg 1989;59:665-7.

13. Gonzalez ME, Selas RP, Bercedo M, García IG, Carazo P, et al. Results of surgical treatment of hepatic hydatidosis: current therapeutic modifications. World J Surg 1991;15:254-63.

14. Dziri C, Haouet K, Fingerhut A. Treatment of hydatid cyst of the liver: where is the evidence? World J Surg 2004;28:731-6.

15. Iskender S, Demiral O. Diagnosis and treatment of uncomplicated hydatid cyst of the liver. World J surg 2001;25:21-7.

16. Buttenschoen K, Buttenschoen CD. Echinococcus granulosus infection: the challenge of surgical treatment. Langenbecks Arch Surg 2003;388:218-30.

17. Doty JE, Tompkins RK. Management of cystic disease of the liver. Surg Clin North Am 1989;69:285.

18. El Malki HO, El Mejdoubi Y, Souadka A, Zakri B, Mohsine R, et al. Does primary surgical management of liver hydatid cyst influence recurrence? J Gastrointest Surg 2010;14:1121-7.

19. Aydin U, Yazici P, Onen Z, Ozsoy M, Zeytunlu M, et al. The optimal treatment of hydatid cyst of the liver: radical surgery with a significant reduced risk of recurrence. Turk J Gastroenterol 2008;19:33-9.

20. Tagliacozzo S, Miccini M, Bonapasta AS, Gregori M, Tocchi A. Surgical treatment of hydatid disease of the liver: 25 years of experience. Am J Surg 2011;201:797-804.

21. Kayaalp C, Sengul N, Akoglu M. Importance of cyst content in hydatid liver surgery. Arch Surg 2002;137:159-63.

22. Arif SH, Shams-UI-Bari, Wani NA, Zarger SA, Wani MA, et al. Albendazole as an adjuvant to the standard surgical management of hydatid cyst liver. Int J Surg 2008;6:448-51. 